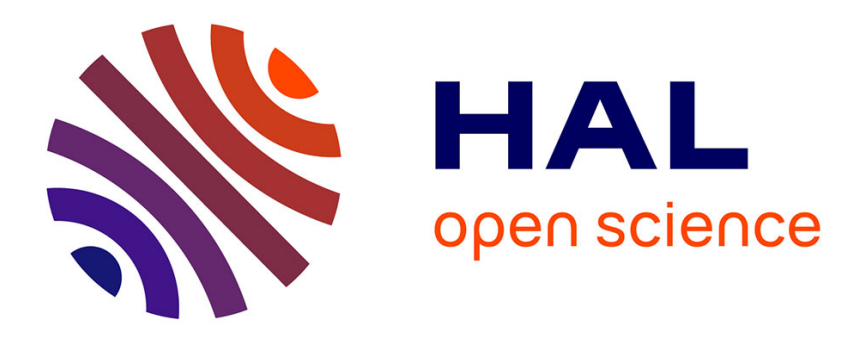

\title{
The dynamics of economic convergence: The role of alternative investment decisions
}

\author{
Jan Brůha, Jiří Podpiera
}

\section{To cite this version:}

Jan Brůha, Jiř́ Podpiera. The dynamics of economic convergence: The role of alternative investment decisions. Journal of Economic Dynamics and Control, 2011, 35 (7), pp.1032. 10.1016/j.jedc.2010.12.016 . hal-00822060

\section{HAL Id: hal-00822060 \\ https://hal.science/hal-00822060}

Submitted on 14 May 2013

HAL is a multi-disciplinary open access archive for the deposit and dissemination of scientific research documents, whether they are published or not. The documents may come from teaching and research institutions in France or abroad, or from public or private research centers.
L'archive ouverte pluridisciplinaire HAL, est destinée au dépôt et à la diffusion de documents scientifiques de niveau recherche, publiés ou non, émanant des établissements d'enseignement et de recherche français ou étrangers, des laboratoires publics ou privés. 


\section{Author's Accepted Manuscript}

The dynamics of economic convergence: The role of alternative investment decisions

Jan Brůha, Jiří Podpiera

PII:

S0165-1889(11)00041-8

DOI:

doi:10.1016/j.jedc.2010.12.016

Reference:

DYNCON 2542

To appear in: $\quad$ Journal of Economic Dynamics

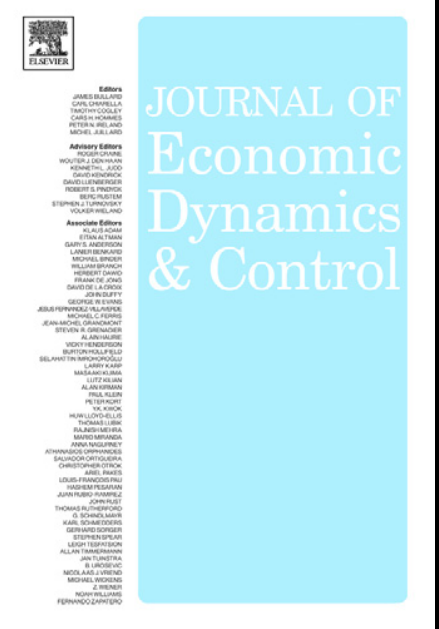
\& Control

www.elsevier.com/locate/jedc

Received date: 21 November 2007

Revised date: 2 August 2010

Accepted date: 19 December 2010

Cite this article as: Jan Brůha and Jiří Podpiera, The dynamics of economic convergence: The role of alternative investment decisions, Journal of Economic Dynamics \& Control, doi:10.1016/j.jedc.2010.12.016

This is a PDF file of an unedited manuscript that has been accepted for publication. As a service to our customers we are providing this early version of the manuscript. The manuscript will undergo copyediting, typesetting, and review of the resulting galley proof before it is published in its final citable form. Please note that during the production process errors may be discovered which could affect the content, and all legal disclaimers that apply to the journal pertain. 


\title{
The Dynamics of Economic Convergence: The Role of Alternative Investment Decisions
}

\author{
Jan Brůha ${ }^{\mathrm{a}, \mathrm{b}}$, Jiří Podpiera ${ }^{\mathrm{c}}$ \\ ${ }^{a}$ The Center for Economic Research and Graduate Education of Charles University and the \\ Economic Institute of the Academy of Sciences \\ Politických vězñu 7, 11121 Praha 1, Czech Republic \\ ${ }^{b}$ Czech National Bank, Na Př́kopě 28, 11503 Praha 1, Czech Republic. \\ ${ }^{c}$ International Monetary Fund, 700 19th Street, N.W., Washington, D.C., 20431
}

\begin{abstract}
In this paper we evaluate how various investment decisions explain the macroeconomic dynamics of European transition countries. We introduce quality investment decisions into a model with other two standard investment margins assumed in the advanced trade literature, i.e., investment in new varieties and in export eligibility. We show that the standard investment margins are not sufficient to simultaneously match the dynamics in the macroeconomic variables, especially the export performance and the real exchange rate. In contrast, the extended model with quality investment provides reconciliation.
\end{abstract}

Keywords: Two-country Modeling, Convergence, Real Exchange Rate J.E.L. Classification: F12, F36, F41.

\section{Introduction}

Macroeconomic dynamics of Central and Eastern European transition countries ${ }^{1}$ (henceforth CEE countries) is puzzling from the perspective of standard dynamic general equilibrium models. The purpose of this paper is to introduce an extension to the existing two-country dynamic general equilibrium models with advanced trade features for understanding the convergence process of emerging market economies.

During a transition decade 1995-2005 (i.e., after the basic institutional foundations of a market economy have been created, Roland, 2004), the following facts (see also Figure 1) dominate the picture of the economic development in CEE countries:

Email addresses: jan.bruha@cnb.cz; jan_bruha@yahoo.co.uk (Jan Brůha), jpodpiera@imf.org (Jiří Podpiera)

${ }^{1}$ These are so-called 4-Visegrad countries, i.e., the Czech Republic, Hungary, Poland, and Slovakia. 
Fact 1: The convergence in GDP per capita of an average Visegrad-4 country to the average of the EU15 attained 1 percent a year on average over the decade.

Fact 2: An increase in export to GDP ratio on average over Visegrad-4 countries attained 2 percent a year over the decade; trade balance, after initial deficit around 5 percent, has reached balanced position at the end of the decade.

Fact 3: Real exchange rates - also in sub-index of tradable goods - of Visegrad4 currencies vis à vis the Euro have been appreciating by an average of about 3 percent a year ${ }^{2}$.

Fact 4: The proportion of medium-high and high tech products in total exports has gained 1.5 to 2 percent a year, see Fabrizio et al. (2007).

We investigate the implications of different modeling assumptions on investment decisions for capturing the macroeconomic dynamics of the transition economies. Modeling benchmarks are recent macroeconomic models with advanced trade features; such as Ghironi and Melitz (2005). This kind of models usually works with two investment margins: horizontal investments in new varieties and investment in export eligibility.

However, Dury and Oomen (2007) and Brůha and Podpiera (2010) suggest that the concurrently observed Fact 2 and Fact 3 calls for an extension of the available framework by changes in quality levels (the vertical investment margin $)^{3}$. Both studies basically associate the deficit of the two-country dynamic general-equilibrium models for explanation of the experience of converging countries to the implicit assumption that along the transition path products of both countries have comparable qualities. Indeed, since relatively more goods (Fact 2) are sold for relatively higher prices (Fact 3), the trend development in Visegrad-4 countries can be only reconciled by a steady improvement in quality of products (Fact 4).

Therefore, we present a model, which treats various investment decisions endogenously and, on aggregate, the decisions influence the real exchange rate and convergence dynamics. The contribution is that (i) we show how to formalize

${ }^{2}$ The real exchange rate appreciation could be a consequence of unbalanced growth in productivities in favor of tradable versus non-tradable sectors which is stronger for fast growing countries. Since the Visegrad-4 countries converge to the developed Western EU countries, they could be prone to such an effect. However, Égert et al. (2006) presents a survey of 14 studies estimating the Harrod-Balassa-Samuelson effect in Visegrad-4 countries using data for productivity growth in tradable as well as non-tradable sectors. The average annual effect is 0.7 percent, which is roughly one third of the observed average close to 3 percent annual real exchange rate appreciation in the region during 1995-2005.

${ }^{3} \mathrm{An}$ increase in product quality enables to export products at higher prices, which is compatible with the structural (equilibrium) real exchange rate appreciation. Hallak and Schott (2008), Cincibuch and Podpiera (2006), and Fabrizio et al. (2007) document an average 4 percent annual increase in relative product quality in the CEE countries compared to various benchmarks during 1989-2004. This is consistent with the increasing proportion of high-tech production in export of Visegrad-4; approx. 2 percent annually between 1995-2005. 
Figure 1: Stylized facts
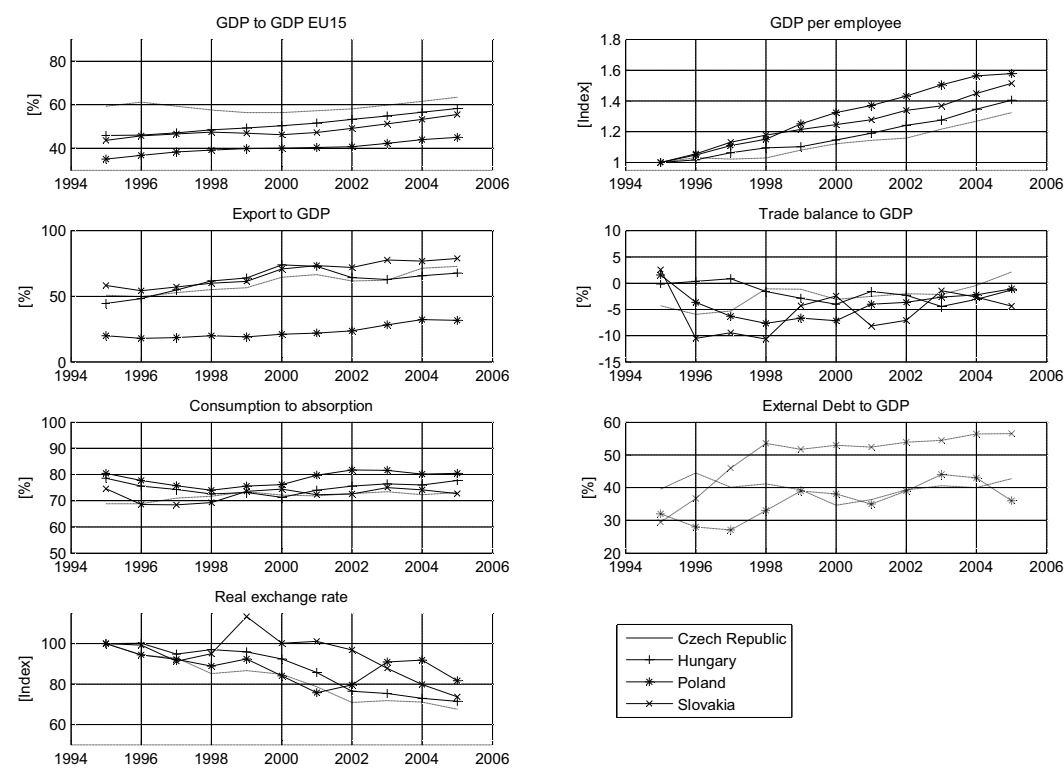

various kinds of investments in a rigorous framework of the dynamic general equilibrium and (ii) we explain their role for macroeconomic dynamics.

The comprehensive two-country modeling framework is formulated with the purpose of capturing long-run trends in main macroeconomic variables of a converging economy. Thus, contrary to the usual practice of applied DSGE models, which attempt to characterize the short-run fluctuations around a steady state or around an exogenously given development trajectory, the proposed model yields a long-run trajectory of convergence of asymmetric countries. Since the stress is on the long-run trends, the model is formulated as a dynamic perfect-foresight model.

The rest of the paper is organized as follows: Section 2 describes the model, Section 3 highlights features of the proposed model by contrasting them with an alternative setup. Section 4 concludes.Appendix A contains a detailed derivation of the model. Moreover, there are two Electronic Appendices related to the paper: Electronic Appendix B discusses the numerical methods for model simulation, while Electronic Appendix $\mathrm{C}$ describes the model extension by the elastic labor supply. The two electronic appendices can be downloaded from http://www.koltech.cz/english/data/JEDC_ElAp.pdf. 


\section{Description of the Model}

There are two countries that are modeled in discrete time that runs from zero to infinity. Each country is populated by a representative competitive household who has recursive preferences over discounted streams of momentary utilities. The momentary utility is derived from consumption. The production takes place in heterogenous production entities called firms.

\subsection{Firms}

In the domestic country, there is a large number of firms, which are owned by the domestic household. In each period there is an unbounded mass of potential, ex-ante identical, entrants. Each entrant has to pay the fixed entry cost $c$; the cost is paid in terms of the aggregate consumption bundle. The actual number of entrants is determined by the zero-profit condition.

Firms differ ex-post entry by an idiosyncratic variation of total factor productivity: when a firm enters, it draws a shock $z$ from a distribution $G(z)$. At the end of each period, there is an exogenous probability that a firm is hit by an exit shock. This probability is $\delta$ and is assumed to be independent of aggregate as well as individual states. Hit firms shut down.

The production of a firm is characterized by two features: physical quantity $x$ and the product quality $h$. If the firm $j$ wishes to produce its product with the quality level $h_{j}$, it has to pay the fixed quality investment at the level $h_{j}$. Similarly to the entry cost, the quality investments take the form of the aggregate consumption bundle. The quality choice is a once-and-for-all decision undertaken at the entry time (but after the idiosyncratic productivity is revealed).

In addition to the quality input $h$, the production requires a variable input -labor $l$. The production of the final bundle $q_{j t}$ can be described using the neoclassical production function $f$ and the firm's total factor productivity $A_{t} z_{j}$, $q_{j t}=z_{j} A_{t} f\left(h_{j}, l_{j t}\right)$. The quality of the final bundle is $h_{j}$, and therefore the physical quantity is given simply as $x_{j t}=q_{j t} / h_{j}$. Such a distinction between the final bundle (quality included) and the physical quantity is standard in the literature; e.g., Young (1998). We explicitly distinguish the quality-quantity bundle from the physical quantity, since the explanation for the observed real exchange rate appreciation is based on a dichotomy between quality-adjusted and-unadjusted prices. This feature conciliates increasing external competitiveness with appreciating real exchange rate $^{4}$.

The production is affected by the level of firm's total factor productivity $A_{t} z_{j}$, which has two components: (a) an idiosyncratic component $z_{j}$, which is i.i.d. across firms and which follows the distribution $G(z)$ introduced above,

\footnotetext{
${ }^{4}$ The quality investment is an endogenous decision and is in our model driven by demand factors. First, as the converging economy becomes richer, its consumers demand higher-quality goods and second, exporters need to invest into quality to compete with firms in the advanced country.
} 
and (b) a common component $A_{t}$. Domestic firms enjoy $A_{t}$, while foreign firms enjoy $A_{t}^{*}$.

Firms may export only if a special fixed cost is invested. If a firm at the entry time decides to invest the fixed export cost, then it becomes eligible to export in all subsequent periods, otherwise it is never eligible to export. Therefore, we call such firms exporters, while the other firms non-exporters. A unit iceberg exporting cost, $\varsigma$, represents transportation cost, policy barriers such as tariffs, while the fixed cost may represent expenditures associated with acquiring necessary expertise, such as legal, business, or accounting issues of the foreign market. The fixed export cost is again paid in terms of the aggregate consumption bundle and is denoted as $c^{x}>0$. This assumption implies, as in Melitz (2003), that in equilibrium there is a cut-off productivity value $\bar{z}$ such that firms with lower idiosyncratic productivity $z_{j}<\bar{z}$ will not invest to become eligible to export, while firms with a sufficiently high productivity level $z_{j} \geq \bar{z}$ will do.

To ease reading the paper, we introduce the following convention. Countries are distinguished by the * superscript: domestic country's variables are without *, while foreign country's variables do have one. The good produced by a firm located in the destination market is denoted by the superscript $d$, while goods imported are denoted by the superscript $m$. Thus $p_{j \tau t}^{d}$ will denote the time $t$ price of a good produced by a vintage $\tau$ firm $j$ located in the domestic country and sold to the domestic market; $p_{j \tau t}^{m}$ is the time $t$ price of a good $j$ imported to the domestic market from the foreign country; while $p_{j \tau t}^{m *}$ would be a price of a good exported from the domestic country to the foreign household. We further assume that prices are denominated in the currency of the market, where the good is sold.

The quality investment is a sunk cost as well as the fixed export cost set at the time of entry, while labor can be freely adjusted. Given a realization of the productivity shock $z_{j}$, the probability of the exit shock $\delta$, and a chosen production plan, the value of a firm is determined by the expected present value of the stream of profits.

Let $\mathbb{P}_{j \tau t}^{e}$ denote the $t$-period real operating profit of a domestic exporter of vintage $\tau$ enjoying the idiosyncratic productivity $z_{j}$, and be given as follows:

$$
\mathbb{P}_{j \tau t}^{e}=\left[\kappa_{t} \frac{p_{j \tau t}^{d}}{P_{t}}+\left(1-\kappa_{t}\right) \frac{\eta_{t}}{1+\varsigma} \frac{p_{j \tau t}^{m *}}{P_{t}^{*}}\right] A_{t} z_{j} f\left(h_{j \tau}, l_{j \tau t}\right)-\mathbb{W}_{t} l_{j \tau t},
$$

where $0 \leq \kappa_{t} \leq 1$ is the output share sold in the domestic market ${ }^{5} ; P_{t}$ is the domestic price level; $P_{t}^{*}$ is the foreign price level; $\eta_{t}$ is the real exchange rate, which is linked to the nominal exchange rate $s_{t}$ as $\eta_{t}=s_{t} P_{t}^{*} / P_{t} ; \varsigma \geq 0$ represents the unit iceberg exporting costs; $\mathbb{W}_{t}$ is the real wage; and $l_{j \tau t}$ is

\footnotetext{
${ }^{5}$ We show in Appendix A (Lemma 1) that in the equilibrium, all domestic exporters export at a particular date $t$ the same share of its production to the foreign market, regardless their vintage $\tau$ or productivity $j$. Therefore, we shall simply write $\kappa_{t}$ instead of $\kappa_{j \tau t}$. The vintage and productivity only determine whether a particular firm is an exporter or not.
} 
the labor demand of the firm. Similarly, the real operating profit of a domestic non-exporter is given as follows:

$$
\mathbb{P}_{j \tau t}^{n}=\frac{p_{j \tau t}^{d}}{P_{t}} A_{t} z_{j} f\left(h_{j \tau}, l_{j \tau t}\right)-\mathbb{W}_{t} l_{j \tau t} .
$$

Analogous definitions apply to the foreign firms as well.

Products of firms of different vintages have different quality levels (since incentives to invest in quality differ as macroeconomic conditions change), and that is why $\mathbb{P}_{j \tau t}^{e}, \mathbb{P}_{j \tau t}^{n}, p_{j \tau t}^{d}$, and $q_{j \tau t}^{d}$ will be, in general, different.

We assume that firm's managers maximize the expected discounted stream of profits. Thus, the value of the profit stream of the domestic firm of vintage $\tau$, enjoying the idiosyncratic productivity level $z_{j}$, is (in real terms):

$V_{\tau}\left(z_{j}\right)=\max _{\mathbf{1}_{j}^{x}, h_{j \tau},\left\{l_{\tau}\right\}} \sum_{t=\tau}^{\infty}(1-\delta)^{t-\tau} \mu_{\tau}^{t}\left[\mathbf{1}_{j \tau}^{x} \mathbb{P}_{j \tau t}^{e}+\left(1-\mathbf{1}_{j \tau}^{x}\right) \mathbb{P}_{j \tau t}^{n}\right]-\left(c+\mathbf{1}_{j \tau}^{x} c^{x}+h_{j \tau}\right)$,

where $\mathbf{1}_{j}^{x}$ is the indicator of exporters (i.e., $\mathbf{1}_{j}^{x}=1$, if the firm $j$ is an exporter and $\mathbf{1}_{j}^{x}=0$ for non-exporters), and the effective discount factor is given as $(1-\delta)^{\tau-t} \mu_{\tau}^{t}$, where $\mu_{\tau}^{t}$ is the marginal rate of intertemporal substitution between dates $\tau$ and $t$. The rate of the intertemporal substitution is defined in Subsection 2.2. The value of the foreign firm is defined analogously.

Note that prices such as $p_{j \tau t}^{d}$ are prices of the final quantity-quality bundles and therefore derived indexes $P_{t}, P_{t}^{*}$, and $\eta_{t}$ are related to aggregations of these final bundles. The prices related to physical quantities are then given by $\wp_{j \tau t}^{d} \equiv h_{j \tau} p_{j \tau t}^{d}$. The discussion about distinct role of prices per quality-quantity bundle and that of prices defined on physical quantities is left to Subsection 2.3.

\subsubsection{Market Structure}

The final good $Q$ in the domestic country is composed of a continuum of quality-quantity bundles (goods), some of which are produced in the domestic country and some are imported. There is an imperfect substitution among these goods, which is modeled using the standard constant-elasticity-of-substitution (CES) function with the parameter $\theta>1$. The aggregate good in the domestic country is defined as:

$$
Q_{t}=\left(\sum_{\tau \leq t}(1-\delta)^{t-\tau}\left[n_{\tau} \int q_{j \tau t}^{d^{\frac{\theta-1}{\theta}}} \mathrm{d} G(j)+n_{\tau}^{*} \int \mathbf{1}_{j \tau}^{x *} q_{j \tau t}^{m^{\frac{\theta-1}{\theta}}} \mathrm{d} G(j)\right]\right)^{\frac{\theta}{\theta-1}},
$$

where $n_{\tau}$ is the number of domestic entrants, who enter the market at time $\tau$. At time $t$, only $(1-\delta)^{t-\tau} n_{\tau}$ of such entrants survive. The final good in the foreign country is defined analogously. The market structure implies the following definition of the aggregate price index:

$$
P_{t}=\left(\sum_{\tau \leq t}(1-\delta)^{t-\tau}\left[n_{\tau} \int p_{j \tau t}^{d^{1-\theta}} \mathrm{d} G(j)+n_{\tau}^{*} \int \mathbf{1}_{j \tau}^{x *} p_{j \tau t}^{m^{1-\theta}} \mathrm{d} G(j)\right]\right)^{\frac{1}{1-\theta}},
$$


where $p_{j \tau t}$ is the time $t$ price of products of the vintage $\tau$ of the firm $j$. The pricing decisions of firms are described by the subsequent equations below. Note that the final good $Q_{t}$ represents both physical quantities as well as qualities and that the price indexes $P_{t}$ and $P_{t}^{*}$ aggregate both: available quantities and qualities. In that sense, these are quality-adjusted price indexes. See section 2.3 for more discussion.

\subsubsection{Optimal Production Plans}

We derive optimal production and investment plans using backward induction for general neoclassical production function. The parametric example of model equations for the Cobb-Douglas production function is given in Appendix A. We present the derivation for a domestic firm, which is easily generalized for a foreign firm.

Let us assume the problem of maximizing the value of a domestic firm. Since there are no labor adjustment costs, labor decisions are made on a period-byperiod basis. Standard results of monopolistically competitive pricing suggest that prices are set as a mark-up over marginal costs. Simultaneously with prices, firms decide $\kappa_{t}$.

Now, let us take the perspective of a non-exporter of vintage $\tau$ and common productivity level $A_{t}$. Its real operating profit $\mathbb{P}_{j \tau t}^{n}$ in a period $t$ is given conditional on non-exporter status, common productivity, and idiosyncratic productivity $z_{j}$, as a solution to the following program:

$$
\mathbb{P}_{j \tau t}^{n}=\max _{l_{j t}}\left\{\frac{p_{j \tau t}^{d}}{P_{t}} A_{t} z_{j} f\left(h_{j \tau}, l_{j t}\right)-\mathbb{W}_{t} l_{j t}\right\} .
$$

Similarly, the real operating profit of an exporter of vintage $\tau$ in a period $t$, $\mathbb{P}_{j \tau t}^{e}$, is given by:

$$
\mathbb{P}_{j \tau t}^{e}=\max _{l_{j t}}\left\{\left(\kappa_{t} \frac{p_{j \tau t}^{d}}{P_{t}}+\left(1-\kappa_{t}\right) \frac{\eta_{t}}{1+\varsigma} \frac{p_{j \tau t}^{m *}}{P_{t}^{*}}\right) A_{t} z_{j} f\left(h_{j \tau}, l_{j \tau t}\right)-\mathbb{W}_{t} l_{j \tau t}\right\} .
$$

The expected present value of the stream of operating profits is given as follows: $\mathbb{P}_{j \tau}^{\xi}=\sum_{t=\tau}^{\infty} \mu_{\tau}^{t}(1-\delta)^{t-\tau} \mathbb{P}_{j \tau t}^{\xi}$, with $\xi \in\{n, e\}$. The expected present values depend on idiosyncratic productivity $z_{j}$, quality investment $h_{j \tau}$, and the future path of productivities, real wages, and demands. The optimal investment decision of a firm, which enjoys a productivity level $z_{j}$, maximizes the value of the firm, which is given as $\mathbf{V}_{\tau}^{\xi}\left(h_{j \tau} \mid z_{j}\right)=\mathbb{P}_{j \tau}^{\xi}-\left(c+\mathbf{1}_{j \tau}^{x} c^{x}+h_{j}\right)$, for $\xi \in\{n, e\}$. The maximization of $\mathbf{V}_{\tau}^{e}\left(h_{j \tau} \mid z_{j}\right)$ (resp. $\mathbf{V}_{\tau}^{n}\left(h_{j \tau} \mid z_{j}\right)$ ) yields the optimal demand for quality investment for exporters (resp. non-exporters), and the value of the firm is:

$$
V_{\tau}^{\xi}\left(z_{j}\right)=\max _{h_{j \tau} \geq 0} \mathbf{V}_{\tau}^{\xi}\left(h_{j \tau} \mid z_{j}\right),
$$

where $\xi \in\{e, n\}$. The value functions $V_{\tau}^{n}\left(z_{j}\right), V_{\tau}^{e}\left(z_{j}\right)$ implicitly define the cut-off value $\bar{z}$, which is the lowest idiosyncratic shock, which makes the export- 
eligibility investment profitable. Thus, it is defined as

$$
\bar{z}_{\tau}=\underset{z_{j}}{\arg \min }\left(V_{\tau}^{e}\left(z_{j}\right) \geq V_{\tau}^{n}\left(z_{j}\right)\right) .
$$

The value of a firm is given by

$$
V_{\tau}\left(z_{j}\right)=\max _{\xi \in\{n, e\}} V_{\tau}^{\xi}\left(z_{j}\right)=\left\{\begin{array}{ll}
V_{\tau}^{e}\left(z_{j}\right) & \text { if } z_{j} \geq \bar{z}_{\tau} \\
V_{\tau}^{n}\left(z_{j}\right) & \text { if } z_{j}<\bar{z}_{\tau}
\end{array},\right.
$$

and the expected value of a new entrant $\mathcal{V}_{\tau}$ is:

$$
\mathcal{V}_{\tau}=\int_{z_{L}}^{z_{u}} V_{\tau}(z) G(\mathrm{~d} z)
$$

This completes the backward induction.

The optimal production plan derived above induces a measure over firms. Denote by $\widetilde{\mathbb{P}}_{\tau t}$ the $t$-time expected ${ }^{6}$ real operating profit of a domestic firm, which enters in time $\tau, \widetilde{\mathbb{P}}_{\tau t}=\int_{z_{L}}^{z_{u}} \mathbb{P}_{j \tau t} G(\mathrm{~d} z)$, and the expected real investment cost under such measure by $\widetilde{c}_{\tau}$, then:

$$
\mathcal{V}_{\tau}=\sum_{\sigma \geq 0} \mu_{\tau}^{\tau+\sigma}(1-\delta)^{\sigma} \widetilde{\mathbb{P}}_{\tau, \tau+\sigma}-\widetilde{c}_{\tau},
$$

where the expected real investment cost consists of three terms:

$$
\widetilde{c}_{\tau}=c+c^{x}\left(1-G\left(\bar{z}_{\tau}\right)\right)+\widetilde{h} .
$$

The first term is the fixed entry cost $c$ paid by all entrants prior the entry; the second term $c^{x}\left(1-G\left(\bar{z}_{\tau}\right)\right)$ is the expected export-eligibility cost (recall that only firms with $z_{j} \geq \bar{z}_{\tau}$ pay the cost). And the final term $\widetilde{h}$ is the expected quality investments, given by: $\widetilde{h}=\int_{z_{L}}^{\bar{z}_{\tau}} h_{j \tau}^{o p t, n} G(\mathrm{~d} z)+\int_{\bar{z}_{\tau}}^{z_{U}} h_{j \tau}^{o p t, e} G(\mathrm{~d} z)$.

\subsection{Households}

The domestic as well as foreign country is populated by a representative competitive household who has recursive preferences over discounted stochastic streams of period utilities. The period utilities are derived from consumption of the aggregate good. Leisure does not enter the utility, so labor is supplied inelastically ${ }^{7}$. The aggregate labor supply in the domestic country is $\mathcal{L}$, while $\mathcal{L}^{*}$ is the aggregate labor supply in the foreign country. Households can trade bonds denominated in the foreign currency.

\footnotetext{
${ }^{6}$ This expectation is taken with respect to the measure given by the optimal production plan.

${ }^{7}$ We consider the model extension with elastic labor supply in an electronic appendix.
} 
The domestic household maximizes

$$
\max U=\sum_{t=0}^{\infty} \beta^{t} u\left(C_{t}\right)
$$

subject to

$$
B_{t}=\left(1+r_{t-1}^{*}\right) B_{t-1}+\frac{-1}{\eta_{t}}\left(C_{t}-\mathbb{W}_{t} \mathcal{L}\right)+\frac{1}{\eta_{t}}\left(\Xi_{t}-\widetilde{c}_{t} n_{t}\right)-\frac{\Psi_{B}}{2} B_{t}^{2}+\mathcal{T}_{t},
$$

where $B_{t}$ is the real bond holding of the domestic household; $C_{t}$ is consumption; $r_{t-1}^{*}$ is the real interest rate on the internationally traded bond; $\Psi_{B}$ represents portfolio adjustment costs, as in Schmitt-Grohe and Uribe (2003) to stabilize the $\operatorname{model}^{8}$; and $\mathcal{T}_{t}$ is the rebate of these costs in a lump-sum fashion to the household. The flow of real operating profits from all domestic firms is denoted as $\Xi_{t}$ and is given by:

$$
\Xi_{t}=\sum_{s \leq t}(1-\delta)^{t-s} n_{s} \widetilde{\mathbb{P}}_{s, t}
$$

Because of the law of large numbers and of perfect foresight, the ex-ante expected values of the key variables for household decisions (such as the investment cost or profit flows) coincide with ex-post realizations.

The first-order conditions for the domestic household are standard ones:

$$
\begin{gathered}
\left(1+\Psi_{B} B_{t}\right)=\frac{\eta_{t+1}}{\eta_{t}}\left(1+r_{t}^{*}\right) \mu_{t}^{t+1}, \\
\widetilde{c}_{t}=\sum_{v \geq 0}(1-\delta)^{v} \mu_{t}^{t+v} \widetilde{\mathbb{P}}_{t, t+v},
\end{gathered}
$$

along with the transversality condition $\lim _{t \rightarrow \infty} B_{t+1}=0$, and where the marginal rate of substitution is defined as usual by :

$$
\mu_{t_{1}}^{t_{2}} \equiv \beta^{t_{2}-t_{1}} \frac{u^{\prime}\left(C_{t_{2}}\right)}{u^{\prime}\left(C_{t_{1}}\right)} .
$$

Equation (7) determines the bond holding, and equation (8) is the expected zero-profit condition, which determines the number of new domestic entrants $n_{t}$.

It is worth noting that although there is an idiosyncratic variance at the firm level, the model is deterministic at the aggregate level, thus the dynasty problem is deterministic too. Therefore the marginal rate of substitution does not involve the expectation operator. The household problem in the foreign country is defined symmetrically.

\footnotetext{
${ }^{8}$ In a strict sense, the model is stable even without portfolio adjustment costs (i.e., under $\left.\Psi_{B}=0\right)$. The model is deterministic and therefore it would not exhibit unit-root behavior even under $\Psi_{B}=0$. Nevertheless, if $\Psi_{B}=0$, then the model would exhibit steady state dependence on the initial asset holding. Therefore we use nontrivial adjustment $\operatorname{costs} \Psi_{B}>0$ to give up the dependence of the steady state on the initial asset holding.
} 
Bonds are denominated in the foreign currency ${ }^{9}$. The international bond market equilibrium requires that $B_{t}+B_{t}^{*}=0$.

To summarize, the timing proceeds first with the entry of prospecting entrants in both countries. Then, each new entrant draws a productivity level from the distribution $G$ and decides the quality of its production $h_{j \tau}$ and whether to invest for export eligibility. Then, labor demand and production (of both entrants and incumbents) take place. At the end of the period, some firms experience the exit shock and shut down.

\subsection{Notes on Price Indexes}

The prices $p_{j \tau t}$ and the corresponding price indexes $P_{t}$ and $P_{t}^{*}$ are qualityadjusted. Therefore, the real wages $\mathbb{W}_{t}$ and $\mathbb{W}_{t}^{*}$ and the real exchange rate $\eta_{t}$ are measured in terms of quality-quantity bundles. These measures correspond to real-world price indexes only if the latter are quality-adjusted perhaps using a hedonic approach, which is rarely the case for transition countries (see Ahnert and Kenny, 2004, p. 28). To get indexes closer to real-world measures, we have to define aggregate indexes over $\wp_{j \tau t}$. We denote such indexes as $\mathcal{P}_{t}$ and $\mathcal{P}_{t}^{*}$.

The quality-unadjusted price index should satisfy the aggregation consistency, i.e., the aggregate expenditure (measured in quality-unadjusted prices) $\mathcal{P}_{t} Q_{t}$ should be equal to the aggregation of the individual (quality-unadjusted) prices. Therefore, the quality-unadjusted price index should be defined as follows:

$$
\mathcal{P}_{t}=\frac{\sum_{\tau \leq t}(1-\delta)^{t-\tau}\left[n_{\tau} \int_{z_{L}}^{z_{U}} q_{j \tau t}^{d} \wp_{j \tau t}^{d} \mathrm{~d} G(j)+n_{\tau}^{*} \int_{\bar{z}_{\tau}}^{z_{U}} q_{j \tau t}^{m} \wp_{j \tau t}^{m} \mathrm{~d} G(j)\right]}{Q_{t}} .
$$

The algebraic form of the quality-unadjusted price index (in terms of productivities $A_{t}, A_{t}^{*}$, and aggregates $\left.Q_{t}, Q_{t}^{*}, P_{t}, P_{t}^{*}, \mathbb{W}_{t}, \mathbb{W}_{t}^{*}\right)$ is given in Electronic Appendix B.2.

Nevertheless, $\mathcal{P}_{t}$ might differ from the CPI-based real-world indexes by one more term. The market structure based on the CES aggregation implies the love-for-variety effect, which means that the welfare-theoretical price index differs from the 'average' price (CPI-based) index by the term $\nu^{\frac{1}{\theta-1}}$, where $\nu$ is the number of available varieties and $\theta$ is the parameter of substitution in the CES function (see (Melitz , 2003) for definition and derivation). Therefore, we distinguish the following two definitions of the real exchange rate:

Quality-adjusted theoretically-consistent RER , $\eta_{t}$, is the real exchange rate, which enters the decisions of agents in the model.

\footnotetext{
${ }^{9}$ The bond is real, which also means that the unit of foreign currency is equivalent to the unit of the foreign consumption bundle. In a stochastic model with incomplete markets, the denomination of bonds may have real (redistributive) effects. This is not an issue here as the exchange rate is not influenced by non-fundamental factors, such as noise traders or risk-premium shocks.
} 
CPI-based (quality-unadjusted) RER is the closest counterpart of the measured real exchange rate and is defined as $\left(\frac{\nu_{t}^{*}}{\nu_{t}}\right)^{\frac{1}{\theta-1}} \frac{\mathcal{P}_{t}^{*} / P_{t}^{*}}{\mathcal{P}_{t} / P_{t}} \eta_{t}$.

The quality-adjusted theoretically consistent real exchange rate $\eta_{t}$ depreciates for the transition country during the convergence due to the downward-sloping demand curve. On the other hand, the CPI-based RER index may appreciate under some conditions, see Section 3 for discussion and intuition.

The number of available varieties in the domestic country can be written as:

$$
\nu_{t}=\sum_{\tau \leq t}(1-\delta)^{t-\tau} n_{\tau}+\sum_{\tau \leq t}(1-\delta)^{t-\tau}\left(1-G\left(\bar{z}_{\tau}^{*}\right)\right) n_{\tau}^{*}
$$

where the first term is the number of domestic firms of different vintages existing at time $t$, while the second term is the number of exporters in the foreign country existing at time $t$. The analogous formula holds also for the number of varieties in the foreign country.

\subsection{General Equilibrium}

The general equilibrium is defined as a time profile of prices such that all households optimize and all markets clear.

The aggregate resource constraint is given as follows:

$$
C_{t}+n_{t} \widetilde{c}_{t}=Q_{t}
$$

the labor market equilibrium requires:

$$
\sum_{\tau \leq t}(1-\delta)^{t-\tau} n_{\tau} \int_{z_{L}}^{z_{U}} l_{j \tau t} \mathrm{~d} G(j)=\mathcal{L}
$$

where $l_{j \tau t}$ is the labor demand by individual firms, and $\mathcal{L}$ is the aggregate, inelastic, labor supply. Analogous market clearing conditions hold in the foreign country.

The international bond market equilibrium requires that

$$
B_{t}+B_{t}^{*}=0 .
$$

The last equilibrium condition is the balance-of-payment equilibrium, which requires that:

$$
B_{t+1}=\left(1+r_{t}^{*}\right) B_{t}+X_{t},
$$

where $X_{t}$ is the value of net real exports of the domestic country expressed in the foreign currency.

A more involved task is to simulate the transition dynamics, because the model is effectively a vintage type model. However, if we rewrite the model in the recursive form (the full set of equations of the model in the first-order form is available in Electronic Appendix B), then a variety of efficient methods can be used to simulate the model. 


\subsection{Steady state}

The steady state is the long-run equilibrium and it is obtained when exogenous parameters (particularly $A$ and $A^{*}$ ) are constant for a sufficiently long period of time. The speed of convergence to the steady state is influenced mainly by parameters $\beta$ and $\delta$.

The steady state is characterized by a number of features. The most important (and intuitive) ones include:

- Zero bond holding $B_{s s}=0$, which is due to adjustment costs $\Psi_{B}$.

- Constant quantities and prices.

- The steady-state effective discount rate reads as $\frac{1}{1-\beta(1-\delta)}$ and the steadystate interest rate $r_{s s}=\beta^{-1}-1$.

- The zero net foreign asset positions implies that the net exports are zero as well.

\section{Inquiry on Model Dynamics}

We make use of the model introduced in the preceding sections to inquire whether the vertical investment margin is a necessary component for a consistent explanation of the key stylized facts of converging economies (represented by the real exchange rate, GDP per capita, trade balance development, and the external debt). The vertical investment margin is alternatively switched on and off by alternative model's calibration and taking limits to the expressions, where necessary. The model with active vertical investment margin is labeled as Benchmark, while the model without vertical margin is labeled as Alternative. The comparison of the two model simulations yields our argument.

\subsection{Calibrating the Model}

We assume that the small and less developed economy experiences an exogenous convergence of the domestic total factor productivity to the level of its large and developed counterpart: $A_{t} \rightarrow A^{*}$. After the convergence is reached $A_{t}=A^{*}$, both economies converge to the steady state; the speed of convergence to the steady state is determined mainly by parameters $\beta$ and $\delta$. The majority of parameters are calibrated in accordance with the choice by Ghironi and Melitz (2005). The calibration for the Benchmark and the Alternative differs in the vertical investment margin calibration.

The simulation experiments are carried out under the Cobb-Douglas production function for production of the quality-quantity basket $f(k, l)=k^{\alpha} l^{1-\alpha}$, the constant-relative-risk-aversion momentary utility function $u$ with the parameter 
of the intertemporal rate of substitution $\epsilon$, and the uniform distribution ${ }^{10}$ for $G(z)$. More details about functional forms and their implications are given in Appendix A.

In the parametrization we assume two countries that have liberalized current and financial accounts of the balance of payments: free debt securities trading, on which is levied a portfolio adjustment cost of $\Psi_{B}=0.025$ (a value similar to (Ghironi and Melitz, 2005)). The trade liberalization is represented by a low value of transaction costs $(\varsigma=0.05)$ and the calibration of the export eligibility $\operatorname{cost} c^{x} / c=1.235$ is similar to that of Ghironi and Melitz (2005). The values of $c$ is calibrated to reflect the consumption-to-absorption and investmentto-absorption ratios observed in the data for the CEE countries (the Czech Republic, Slovakia, Hungary, and Poland). These ratios (both in the data ${ }^{11}$ and in the model) are about $70 \%$ and $30 \%$, respectively.

In both countries there is an average mark-up over marginal cost of 28 percent, which falls into the conventional calibration range in the literature. Standard macroeconomic models, such as Rotemberg and Woodford (1992), use $\theta=6$, while Ghironi and Melitz (2005) opt for a value of 3.8 (based on empirically found mark-ups for the U.S. by Bernard et al. (2003). Since the difference in the two mentioned models is in the presence or absence of entry cost, the interpretation of the average vs. marginal costs is crucial. While the mark-up over average and over marginal cost are equal in the model without entry cost, the model with entry cost has different mark-up over marginal and over average cost. Consequently, a model with entry cost and lower $\theta$ would correspond to the same mark-up over average cost in a model with higher $\theta$ and without entry cost. Based on the evidence of mark-ups over average costs in the Czech Republic, provided by Podpiera and Raková (2008), in the range of 15-20 percent, we set the elasticity of substitution at 4.5.

The calibration of the extent, to which the quality investment influences the production of quality-quantity basket, i.e., the parameter $\alpha$, is set to 0.35 for the Benchmark and zero for the Alternative model. The former value is based on the calibration experiments with regard to the pace of the real exchange rate development in the CEE countries during 1995-2005. The choice of the elasticity of intertemporal substitution $\epsilon$ and the discount factor $\beta$ are based on conventional calibration in the literature, i.e., 2 and 95 percent, respectively, which is an annual equivalent to the quarterly calibration in Ghironi and Melitz

\footnotetext{
${ }^{10}$ Microeconomists usually use other distributions than uniform for modelling the distribution of productivities across firms. The usual choice is the Pareto distribution. This practise is followed by Ghironi and Melitz (2005). The problem with the Pareto distribution is that it restricts the parameter $\theta$, since for large values of $\theta$, the value of a new entrant may not be bounded (due to the shape of the Pareto distribution). That is why we use a distribution with the bounded support (i.e. uniform). Moreover, the uniform distribution shares some useful properties with the Pareto distribution (the both distributions are preserved under truncation).

${ }^{11}$ Note that when dealing with the absorption in data, we divide the government consumption into consumption and investments. This is necessary for comparison of the model with data, since the model abstracts from the public sector.
} 
(2005). The annual exit rate for companies $\delta$ is 10 percent, which is the number used by Ghironi and Melitz (2005).

The simulations run from 1995 to 2100 . It is assumed that by 2040 the convergence is completed, i.e. by 2040 the difference in total factor productivity is negligible. Years beyond 2040 are simulated in order to settle the model in the steady state. Table 1 provides an overview of calibrated parameters.

Table 1: Model's Parametrization

\begin{tabular}{|l||c|c|}
\hline \multicolumn{1}{|l||}{ Parameter } & $\begin{array}{c}\text { Benchmark Model } \\
\text { Model with quality investment }\end{array}$ & $\begin{array}{c}\text { Alternative Model } \\
\text { Model without quality investment }\end{array}$ \\
\hline \hline$\alpha$ & 0.35 & 0 \\
$\theta$ & 4.50 & 4.50 \\
$\beta$ & 0.95 & 0.95 \\
$\delta$ & 0.10 & 0.10 \\
$\varsigma$ & 0.05 & 0.05 \\
$\varepsilon$ & 2 & 2 \\
$c^{x}$ & 0.25 & 0.25 \\
$c$ & 1.0 & 1.0 \\
$\Psi_{B}$ & 0.025 & 0.025 \\
$A^{*}$ & 1 & 1 \\
\hline
\end{tabular}

The TFP of the converging economy $A_{t}$ grows according to the logistic curve $A_{t}=A^{*} \frac{1+m \exp (-(t-1995) / \iota)}{1+n \exp (-(t-1995) / \iota)}$, with the following numerical values: $m=7.5$ (for the Benchmark model), $m=6.5$ (for the Alternative model), $n=11$, and $\iota=5$. These values imply that the initial total factor productivity of the converging economy reaches a slightly more than $60 \%$ of the value of the advanced country. This is motivated by the initial position of a typical transition country from the CEE. Note that the parameter $m$ differs in the two model versions; the reason for this calibration is to obtain the identical initial conditions for the output ratio.

\subsection{Simulation results}

The output of the simulations for both the Benchmark and the Alternative model is displayed in Figure 2 and is represented by a set of five variables: the ratio of per capita GDP in the less developed country over that in the developed counterpart, an index of the welfare-theoretical real exchange rate $\eta_{t}$, the empirical real exchange rate (the index of the quality-unadjusted CPI-based real exchange rate), trade balance (as a percentage of the converging country GDP), and external debt of the converging country, i.e., its international bond holding position (expressed in a percentage of the converging country GDP).

In the Benchmark model, the convergence of the less developed country is characterized by halving the gap between GDP per capita within 15 years, empirical exchange rate appreciation by $40 \%$ by the end of convergence, and the welfare-theoretic real exchange rate depreciation by $2.5 \%$. The initial trade 
balance deficit, reaching the lowest level of $5.7 \%$, is turning subsequently into surplus of roughly $5 \%$ in 15 years. And finally, the temporary accumulation of debt to GDP ratio towards the size of $60 \%$ is gradually reduced later.

In a comparison of the Alternative to the Benchmark, the absence of the quality investment in the Alternative causes a slightly faster closure of the convergence gap; the half of the gap is reached in roughly 13 years. However, the empirical real exchange rate appreciates very negligibly (which suggests that the effect of new varieties is rather small) and the real exchange rate depreciates by roughly $2.5 \%$. The major effect comes again from the consumption smoothing mechanism during the convergence in perfect foresight models. In particular, the dynamics of the trade balance exhibits similar pattern as in the Benchmark.

The simulation results for the Benchmark and the Alternative reveal that the introduction of the vertical investment does not change significantly the dynamics of other variables, but implies a significant appreciation of the empirical real exchange rate for the converging economy. It follows that in order to explain concurrently observed Fact 1, 2, and 3, stated in Introduction, one needs to extend the standard framework with the vertical investment margin (documented in Fact 4).

Figure 2: Simulation results
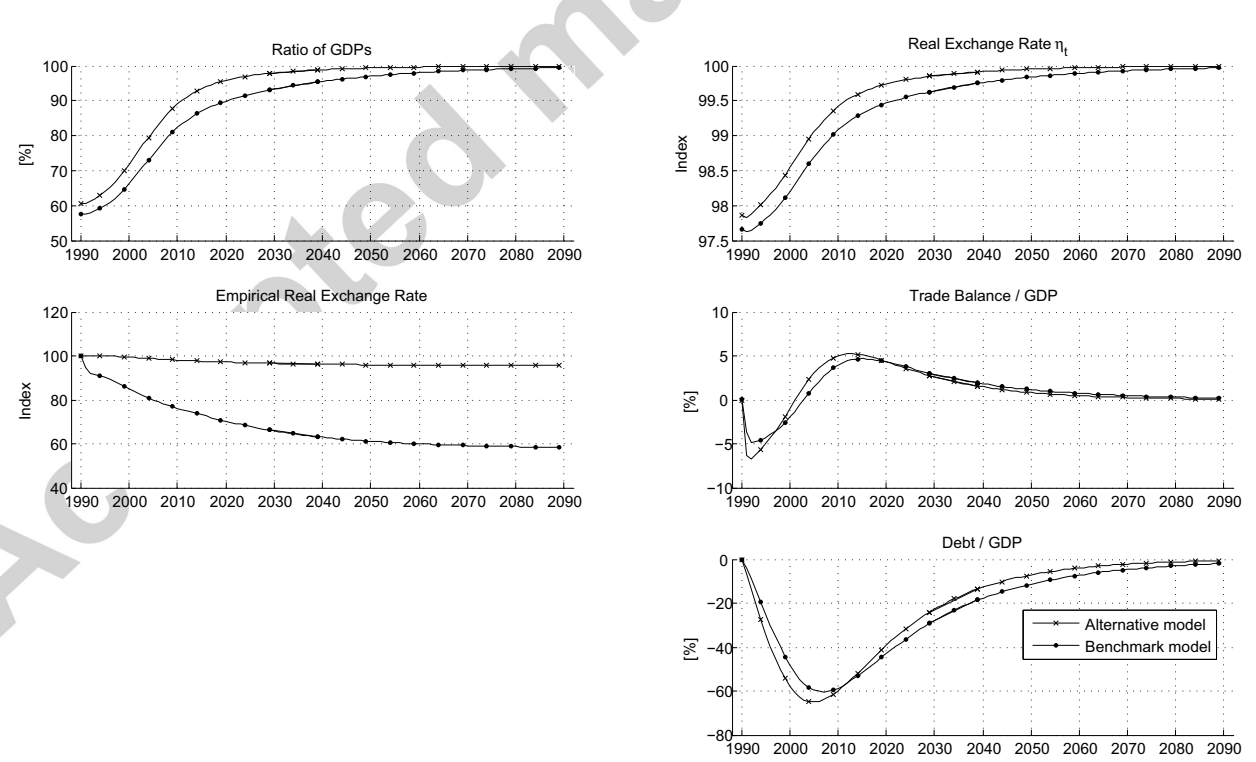


\subsection{Sensitivity analysis}

We start with the parameter $\Psi_{B}$, which does not influence the steady state (and therefore the long-run exchange rate appreciation), but significantly affects the transitory dynamics. Its larger value than chosen would reduce consumption smoothing and therefore the debt accumulation and trade imbalances would be lower during the convergence. The transition dynamics is influenced also by the parameter of the intertemporal substitution $\varepsilon$ (lower values than chosen mean lower incentives to smooth consumption), $\beta$ (higher values than chosen increase patience and therefore reduce the debt accumulation by the converging economy), and $\delta$ (higher values speed up the convergence process since old vintages are being rapidly replaced by new vintages).

The 'openness parameters' (fixed costs $c^{x}$ and iceberg costs $\varsigma$ ) impact the real exchange rate appreciation by reducing the extent of both 'endogenous' Harrod-Balassa-Samuelson effect as well as the quality channel. In fact, if the converging economy is more open at the beginning of the transition, then its real exchange rate is relatively stronger compared to the situation of initially less open transition economy. Therefore, there is lower scope for the real exchange rate adjustment in an initially more open converging economy.

And finally, the parameter of intratemporal substitution $\theta$ affects the exchange rate dynamics as follows: low values of $\theta$ (i.e. low substitution) increase the lovefor-variety effect of the CES utility function, which means that the empirical real exchange rate appreciation would be somewhat stronger even for the model without quality investment (Alternative model). Still, even an extreme calibration, such as $\theta=3$, would not make the love-for-variety effect on the empirical real exchange rate strong enough to replicate the real exchange rate appreciation observed in Visegrad-4 countries.

\section{Conclusion}

In this paper, we describe an extension of two-country models in the literature for quality investment decision and show that such an extension is necessary for a consistent explanation of key macroeconomic variables in transition converging economies. The major conceptual difference from the current literature stems from modeling the explicit decision about investment in quality in two countries, which are unequally developed. From the technical point of view, the difference in the modeling approach, compared to the literature, is in the use of dynamic simulations for solving the model.

The paper presents simulations for two alternative models. First, a rather standard two-country model, in which only investment in varieties and export eligibility is considered. Such a model is shown to generate dynamics in many macroeconomic variables, which matches the data quite well. Nevertheless, the dynamics in the real exchange rate is very subdued. Consequently, it, by far, misses the dynamics observed in Visegrad-4 countries. The second model, which embraces the endogenous decision about investment in quality, is shown to perform equally well in matching macroeconomic variables but, in addition, it also matches well the real exchange rate development. 
As it follows from the results, the proposed extension is of crucial importance for consistent explanation of the macroeconomic developments in the Visegrad-4 region. Bringing the real exchange rate in line with the other macroeconomic variables (such as export performance) offers a reconciliation of the recent puzzle of the limited effect of the real exchange rate appreciation on external competitiveness in transition countries.

\section{Acknowledgement}

The authors would like thank to the editor Michel Juillard and two anonymous referees for very helpful comments and suggestions. The opinions expressed in the article are those of the authors and do not represent the views of the International Monetary Fund and the Czech National Bank. This research project has been also in part supported by the grant Economic Aspects of EU and EMU Entry (No. AVZ70850503) from the Academy of Sciences of the Czech Republic.

\section{Appendix A. Detailed Derivation of the Model}

In this part of the paper, we derive the main model equations for particular functional forms of the production function, utility function, and investment cost functions. In particular, we use the Cobb-Douglas production function $f(k, l)=$ $k^{\alpha} l^{1-\alpha}$ for the production of the quality-quantity bundle. The momentary utility function is parameterized using the common constant-relative-risk-aversion form $u(C)=(1-\varepsilon)^{-1} C^{1-\varepsilon}$, with the parameter of intertemporal substitution $\varepsilon$.

The short-run cost function associated with the Cobb-Douglas production function is given as follows:

$$
\mathbb{C}\left(q, \mathbb{W}_{t}, A_{t}, z_{j}, h_{j \tau}\right)=\mathbb{W}_{t}\left[\frac{q}{A_{t} z_{j} h_{j \tau}^{\alpha}}\right]^{\frac{1}{1-\alpha}} .
$$

First, we derive the maximizing behavior of non-exporters ${ }^{12}$. The period $t$ supply decision of a vintage $\tau$ non-exporter, who enjoys the productivity $z_{j}$, and who has invested in the product quality $h_{j \tau}$, is a solution to the following $\operatorname{program}^{13}$ :

$$
\max _{q_{j \tau t}^{d}}\left\{\left[q_{j \tau t}^{d}\right]^{\frac{\theta-1}{\theta}} Q_{t}^{\frac{1}{\theta}}-\mathbb{C}\left(q_{j \tau t}^{d}, \mathbb{W}_{t}, A_{t}, z_{j}, h_{j \tau}\right)\right\}
$$

\footnotetext{
${ }^{12}$ We derive expressions only for domestic firms. The expression for foreign firms are easily derived analogously.

${ }^{13}$ Note that this program is equivalent to the program (3). The reason is that the quality level $h_{j \tau}$ and the export-eligibility status has been already decided. Therefore the problem of the output choice $q_{j \tau t}$ is perfectly equivalent to the choice of the only variable input (labor) $l_{j \tau t}$. In the derivation, we use the properties of the CES market structure: the real turnover is $\frac{p_{j \tau t}^{d}}{P_{t}} q_{j \tau t}^{d}=\left(q_{j \tau t}^{d}\right)^{\frac{-1}{\theta}} Q_{t}^{\frac{1}{\theta}} q_{j \tau t}^{d}=\left(q_{j \tau t}^{d}\right)^{\frac{\theta-1}{\theta}} Q_{t}^{\frac{1}{\theta}}$ by the residual demand function:
} 
A simple algebra yields the optimal supply:

$$
q_{j \tau t}^{d}=\left(\left[\frac{\theta-1}{\theta}(1-\alpha) \mathbb{W}_{t}^{-1}\left[A_{t} z_{j} h_{j \tau}^{\alpha}\right]^{\frac{1}{1-\alpha}}\right]^{\theta} Q_{t}\right)^{\frac{(1-\alpha)}{\alpha(\theta-1)+1}}
$$

and the optimal labor demand:

$$
l_{j \tau t}=\left[\frac{q_{j \tau t}^{d}}{A_{t} z_{j} h_{j \tau}^{\alpha}}\right]^{\frac{1}{1-\alpha}}=\left(\left[\frac{\theta-1}{\theta}(1-\alpha) \mathbb{W}_{t}^{-1}\right]^{\theta}\left[A_{t} z_{j} h_{j \tau}^{\alpha}\right]^{\theta-1} Q_{t}\right)^{\frac{1}{\alpha(\theta-1)+1}}
$$

Now, using the CES market structure, it is easy to derive the real turnover:

$$
\frac{p_{j \tau t}^{d}}{P_{t}} q_{j \tau t}^{d}=z_{j}^{\frac{\theta-1}{\alpha(\theta-1)+1}} h_{j \tau}^{\frac{\alpha(\theta-1)}{\alpha(\theta-1)+1}}\left[\frac{\theta-1}{\theta}(1-\alpha) \mathbb{W}_{t}^{-1} A_{t}^{\frac{1}{1-\alpha}}\right]^{\frac{(\theta-1)(1-\alpha)}{\alpha(\theta-1)+1}} Q_{t}^{\frac{1}{\alpha(\theta-1)+1}},
$$

and the real operating profit ${ }^{14}$ :

$\mathbb{P}_{j \tau t}=\frac{p_{j \tau t}^{d}}{P_{t}} q_{j \tau t}^{d}-\mathbb{C}\left(q_{j t}^{d}, \mathbb{W}_{t}, A_{t}, z_{j}, h_{j \tau}\right)=\mathcal{W}_{1} z_{j}^{\frac{\theta-1}{\alpha(\theta-1)+1}} h_{j \tau}^{\frac{\alpha(\theta-1)}{\alpha(\theta-1)+1}} \mathbb{W}_{t}^{\frac{-(\theta-1)(1-\alpha)}{\alpha(\theta-1)+1}} A_{t}^{\frac{(\theta-1)}{\alpha(\theta-1)+1}} Q_{t}^{\frac{1}{\alpha(\theta-1)+1}}$

Second, the optimal production decisions of exporters is derived. The problem can be characterized as follows (with the definition $q_{j \tau t}=\kappa_{j \tau t} q_{j \tau t}^{d}+(1-$ $\left.\left.\kappa_{j \tau t}\right) q_{j \tau t}^{m *}\right)$ :

$$
\max _{q_{j \tau t}^{d}, q_{j \tau t}^{m *}}\left\{\left(q_{j \tau t}^{d}\right)^{\frac{\theta-1}{\theta}} Q_{t}^{\frac{1}{\theta}}+\left(\frac{\eta_{t}}{1+\varsigma}\right) Q_{t}^{* \frac{1}{\theta}}\left(q_{j \tau t}^{m *}\right)^{\frac{\theta-1}{\theta}}-\mathbb{C}\left(q_{j \tau t}, \mathbb{W}_{t}, A_{t}, z_{j}, h_{j \tau}\right)\right\}
$$

The solution yields that $q_{j \tau t}^{d}=\left[\frac{\theta-1}{\theta}\left(\frac{\partial \mathbb{C}}{\partial q_{j \tau t}}\right)^{-1}\right]^{\theta} Q_{t}$, and $q_{j \tau t}^{* m}=\left[\frac{\theta-1}{\theta} \frac{\eta_{t}}{1+\varsigma}\left(\frac{\partial \mathbb{C}}{\partial q_{j \tau t}}\right)^{-1}\right]^{\theta} Q_{t}^{*}$.

Some simple, but tedious, algebraic manipulations yield:

$$
\kappa_{j \tau t} q_{j \tau t} \equiv q_{j \tau t}^{d}=\left[\frac{\theta-1}{\theta}(1-\alpha) \mathbb{W}_{t}^{-1}\left(A_{t} z_{j} h_{j \tau}^{\alpha}\right)^{\frac{1}{1-\alpha}}\right]^{\theta} \frac{Q_{t}}{q_{j t}^{\frac{\alpha \theta}{1-\alpha}}},
$$

and

$$
\begin{aligned}
& \left(1-\kappa_{j \tau t}\right) q_{j \tau t} \equiv q_{j \tau t}^{m *}=\left[\frac{\theta-1}{\theta}(1-\alpha) \frac{\eta_{t}}{1+\varsigma} \mathbb{W}_{t}^{-1}\left(A_{t} z_{j} h_{j \tau}^{\alpha}\right)^{\frac{1}{1-\alpha}}\right]^{\theta} \frac{Q_{t}^{*}}{q_{j \tau t}^{\frac{\alpha \theta}{1-\alpha}}} . \\
& \frac{p_{j \tau t}^{d}}{P_{t}}=\left(\frac{q_{j \tau t}^{d}}{Q_{t}}\right)^{\frac{-1}{\theta}} \cdot \\
& { }^{14} \mathrm{We} \quad \text { define } \quad \mathcal{W}_{1} \equiv\left[\frac{\theta-1}{\theta}(1-\alpha)\right]^{\frac{(\theta-1)(1-\alpha)}{\alpha(\theta-1)+1}}-\left[\frac{\theta-1}{\theta}(1-\alpha)\right]^{\frac{\theta}{\alpha(\theta-1)+1}}= \\
& \frac{\alpha(\theta-1)+1}{(\theta-1)(1-\alpha)}\left[\frac{\theta-1}{\theta}(1-\alpha)\right]^{\frac{\theta}{\alpha(\theta-1)+1}} .
\end{aligned}
$$


This implies that $\kappa_{j \tau t}=\frac{Q_{t}}{Q_{t}+Q_{t}^{*}\left(\frac{\eta_{t}}{1+\varsigma}\right)^{\theta}}$. Observe that $\kappa_{j \tau t}$ does not depend on individual characteristics of firms: $z_{j}$ and $h_{j \tau}$; it depends only on relative tightness of both markets and on the real exchange rate corrected for transport costs $\varsigma$. Therefore, we just proved the following Lemma:

Lemma 1: It is never optimal for exporters to export all production and not to export in a given period. Moreover, the optimal exporting share $\kappa_{t}$ depends only on the current macroeconomic conditions, and - given the exporting status of a firm - it does not depend on its vintage or on its productivity.

Thus, we will simply write $\kappa_{t}$ instead of $\kappa_{j \tau t}$. Define $\xi_{t} \equiv Q_{t}+Q_{t}^{*}\left(\frac{\eta_{t}}{1+\varsigma}\right)^{\theta}=$ $\frac{Q_{t}}{\kappa_{t}}$. The total production of eligible firms can be written as follows:

$$
q_{j \tau t}=\left(z_{j}^{\theta} h_{j \tau}^{\alpha \theta}\right)^{\frac{1}{\alpha(\theta-1)+1}}\left\{\left[\frac{\theta-1}{\theta}(1-\alpha) \mathbb{W}_{t}^{-1} A_{t}^{\frac{1}{1-\alpha}}\right]^{\theta} \xi_{t}\right\}^{\frac{(1-\alpha)}{\alpha(\theta-1)+1}},
$$

and the optimal labor demand:

$$
l_{j \tau t}=\left[\frac{q_{j \tau t}}{A_{t} z_{j} h_{j \tau}^{\alpha}}\right]^{\frac{1}{1-\alpha}}=\left(\left[\frac{\theta-1}{\theta}(1-\alpha) \mathbb{W}_{t}^{-1}\right]^{\theta}\left[A_{t} z_{j} h_{j \tau}^{\alpha}\right]^{\theta-1} \xi_{t}\right)^{\frac{1}{\alpha(\theta-1)+1}}
$$

The firms' real turnovers on the domestic and the foreign markets, respectively are given by:

$$
\begin{aligned}
& \frac{p_{j \tau t}^{d}}{P_{t}} q_{j \tau t}^{d}=z_{j}^{\frac{\theta-1}{\alpha(\theta-1)+1}} h_{j \tau}^{\frac{\alpha(\theta-1)}{\alpha(\theta-1)+1}} \kappa_{t}^{\frac{\alpha(\theta-1)}{\alpha(\theta-1)+1}}\left[\frac{\theta-1}{\theta}(1-\alpha) \mathbb{W}_{t}^{-1} A_{t}^{\frac{1}{1-\alpha}}\right]^{\frac{(\theta-1)(1-\alpha)}{\alpha(\theta-1)+1}} Q_{t}^{\frac{1}{\alpha(\theta-1)+1}}, \\
& \left(\frac{\eta_{t}}{1+\varsigma}\right) \frac{p_{j \tau t}^{m *}}{P_{t}^{*}} q_{j t}^{m *}=z_{j}^{\frac{\theta-1}{\alpha(\theta-1)+1}} h_{j \tau}^{\frac{\alpha(\theta-1)}{\alpha(\theta-1)+1}}\left(1-\kappa_{t}\right)^{\frac{\alpha(\theta-1)}{\alpha(\theta-1)+1}}\left(\frac{\eta_{t}}{1+\varsigma}\right)^{\frac{\theta}{\alpha(\theta-1)+1}} \times \\
& \times\left[\frac{\theta-1}{\theta}(1-\alpha) \mathbb{W}_{t}^{-1} A_{t}^{\frac{1}{1-\alpha}}\right]^{\frac{(\theta-1)(1-\alpha)}{\alpha(\theta-1)+1}} Q_{t}^{* \frac{1}{\alpha(\theta-1)+1}}
\end{aligned}
$$

Real production costs of exporters read as follows:

$$
\mathbb{C}_{j t}=z_{j}^{\frac{\theta-1}{\alpha(\theta-1)+1}} h_{j \tau}^{\frac{\alpha(\theta-1)}{\alpha(\theta-1)+1}} A_{t}^{\frac{(\theta-1)}{\alpha(\theta-1)+1}} \mathbb{W}_{t}^{\frac{-(\theta-1)(1-\alpha)}{\alpha(\theta-1)+1}}\left\{\left[\frac{\theta-1}{\theta}(1-\alpha)\right]^{\theta} \xi_{t}\right\}^{\frac{1}{\alpha(\theta-1)+1}}
$$

thus, the real operating profit in a period $t$ is given as:

$$
\mathbb{P}_{j \tau t}^{e}=\mathcal{W}_{1} z_{j}^{\frac{\theta-1}{\alpha(\theta-1)+1}} h_{j \tau}^{\frac{\alpha(\theta-1)}{\alpha(\theta-1)+1}} A_{t}^{\frac{(\theta-1)}{\alpha(\theta-1)+1}} \mathbb{W}_{t}^{\frac{-(\theta-1)(1-\alpha)}{\alpha(\theta-1)+1}} \xi_{t}^{\frac{1}{\alpha(\theta-1)+1}}
$$


Now, we are able to derive the expected present value of profit stream. We start with an exporter $\mathbb{P}_{j \tau}^{e}$, whose expected present value satisfies:

$$
\mathbb{P}_{j \tau}^{e}=z_{j}^{\frac{\theta-1}{\alpha(\theta-1)+1}} h_{j \tau}^{\frac{\alpha(\theta-1)}{\alpha(\theta-1)+1}} \underbrace{\mathcal{W}_{1} \sum_{t=\tau}^{\infty}(1-\delta)^{t-\tau} \mu_{\tau}^{t} A_{t}^{\frac{(\theta-1)}{\alpha(\theta-1)+1}} \mathbb{W}_{t}^{\frac{-(\theta-1)(1-\alpha)}{\alpha(\theta-1)+1}} \xi_{t}^{\frac{1}{\alpha(\theta-1)+1}}}_{\varpi_{\tau}^{e}},
$$

while the expected present value of a non-exporter $\mathbb{P}_{j \tau}^{n}$ satisfies:

$$
\mathbb{P}_{j \tau}^{n}=z_{j}^{\frac{\theta-1}{\alpha(\theta-1)+1}} h_{j \tau}^{\frac{\alpha(\theta-1)}{\alpha(\theta-1)+1}} \underbrace{\mathcal{W}_{1} \sum_{t=\tau}^{\infty}(1-\delta)^{t-\tau} \mu_{\tau}^{t} A_{t}^{\frac{(\theta-1)}{\alpha(\theta-1)+1}} \mathbb{W}_{t}^{\frac{-(\theta-1)(1-\alpha)}{\alpha(\theta-1)+1}} Q_{t}^{\frac{1}{\alpha(\theta-1)+1}}}_{\varpi_{\tau}^{n}}
$$

The value of an exporter, who enjoys a productivity level $z_{j}$, is determined by quality investment:

$$
\mathbf{V}_{\tau}^{e}\left(h_{j \tau} \mid z_{j}\right)=\mathbb{P}_{j \tau}^{e}-\left(c+c^{x}+h_{j \tau}\right) \equiv z_{j}^{\frac{\theta-1}{(1-\alpha)+\alpha \theta}} h_{j \tau}^{\frac{\alpha(\theta-1)}{(1-\alpha)+\alpha \theta}} \varpi_{\tau}^{e}-\left(c+c^{x}+h_{j \tau}\right) ;
$$

and similarly for a non-exporter:

$$
\mathbf{V}_{\tau}^{n}\left(h_{j \tau} \mid z_{j}\right)=\mathbb{P}_{j \tau}^{n}-\left(c+h_{j \tau}\right)=z_{j}^{\frac{\theta-1}{(1-\alpha)+\alpha \theta}} h_{j \tau}^{\frac{\alpha(\theta-1)}{(1-\alpha)+\alpha \theta}} \varpi_{\tau}^{n}-\left(c+h_{j \tau}\right) .
$$

If firms' manager maximizing the value of the firm chooses the following quality level:

$$
h_{j \tau}^{o p t, e}=z_{j}^{\theta-1}\left[\frac{\alpha(\theta-1) \varpi_{\tau}^{e}}{\alpha(\theta-1)+1}\right]^{\alpha(\theta-1)+1}
$$

and the value of an exporting firm is ${ }^{15}$ :

$$
V_{\tau}^{e}\left(z_{j}\right)=\max _{h \geq 0} \mathbf{V}_{\tau}^{e}\left(h \mid z_{j}\right)=z_{j}^{(\theta-1)}\left[\varpi_{\tau}^{e}\right]^{\alpha(\theta-1)+1} \mathcal{G}-\left(c+c^{x}\right),
$$

similarly, the value of a non-exporting firm is

$$
V_{\tau}^{d n}\left(z_{j}\right)=\max _{h \geq 0} \mathbf{V}_{\tau}^{d n}\left(h \mid z_{j}\right)=z_{j}^{\theta-1}\left[\varpi_{\tau}^{n}\right]^{\alpha(\theta-1)+1} \mathcal{G}-c,
$$

and the optimal investment to quality is:

$$
h_{j \tau}^{o p t, n}=z_{j}^{\theta-1}\left[\frac{\alpha(\theta-1) \varpi_{\tau}^{n}}{\alpha(\theta-1)+1}\right]^{\alpha(\theta-1)+1} .
$$

\footnotetext{
${ }^{15}$ Define $\mathcal{G} \equiv\left[\left(\frac{\alpha(\theta-1)}{\alpha(\theta-1)+1}\right)^{\alpha(\theta-1)}-\left(\frac{\alpha(\theta-1)}{\alpha(\theta-1)+1}\right)^{\alpha(\theta-1)+1}\right]$, which can be simplified to $\mathcal{G}=$ $\frac{1}{\alpha(\theta-1)+1}\left(\frac{\alpha(\theta-1)}{\alpha(\theta-1)+1}\right)^{\alpha(\theta-1)}$.
} 
The value functions $V_{\tau}^{n}\left(z_{j}\right)$, and $V_{\tau}^{e}\left(z_{j}\right)$ implicitly define the cut-off value $\bar{z}$, which is the least idiosyncratic shock, which makes the export-eligibility investment profitable, i.e. $\bar{z}_{\tau}=\underset{z_{j}}{\arg \min }\left(V_{\tau}^{e}\left(z_{j}\right) \geq V_{\tau}^{n}\left(z_{j}\right)\right)$, which for the particular parametrization is given as follows:

$$
\bar{z}_{\tau}=\left(\frac{c^{x}}{\mathcal{G}\left[\left[\varpi_{\tau}^{e}\right]^{\alpha(\theta-1)+1}-\left[\varpi_{\tau}^{n}\right]^{\alpha(\theta-1)+1}\right]}\right)^{\frac{1}{\theta-1}} .
$$

Note that the definition of the cut-off value is correct, only if the expected present value of profit is increasing in $z_{j}$. The proposition below demonstrates that this is indeed the case:

Lemma 2: The net present value of the stream of exporter's real operating profits $\mathbb{P}_{j \tau}^{e}$ is increasing in $z_{j}$, and similarly for non-exporters. Moreover, for any $z_{j}$ and $\tau: \mathbb{P}_{j \tau}^{e}>\mathbb{P}_{j \tau}^{n}$.

Proof: The first part of the claim is a direct application of the envelope theorem. Indeed, the envelope theorem ensures that $\frac{d \mathbb{P}_{j \tau t}^{e}}{d z_{j}}=\frac{\partial \mathbb{P}_{j \tau t}^{e}}{\partial z_{j}}$. By (3) one obtains that $\frac{\partial \mathbb{P}_{j \tau t}^{e}}{\partial z_{j}}=\frac{\theta-1}{\theta z_{j}}\left[A_{t} z_{j} f\left(h_{j \tau}, l_{j t}\right)\right]^{\frac{\theta-1}{\theta}} Q_{t}^{\frac{1}{\theta}}$, which is clearly positive for any finite $z_{j}, A_{t}$, and $Q_{t}$. Therefore $\frac{d \mathbb{P}_{j \tau}^{e}}{d z_{j}}=\sum_{t=\tau}^{\infty} \mu_{\tau}^{t}(1-\delta)^{t-\tau} \frac{d \mathbb{P}_{j \tau t}^{e}}{d z_{j}}=\sum_{t=\tau}^{\infty} \mu_{\tau}^{t}(1-$ $\delta)^{t-\tau} \frac{\partial \mathbb{P}_{j t t}^{e}}{\partial z_{j}}>0$. The exactly analogous reasoning applies for exporters. This proves the first part of Lemma. To prove the second part of Lemma, observe that the exporter can secure at least as high profit as the non-exporter by choosing $\kappa \equiv 1$, and by choosing the same level of the quality investment $h_{j \tau}$. Therefore $\mathbb{P}_{j \tau}^{e} \geq \mathbb{P}_{j \tau}^{n}$. The strict inequality follows from the fact that $0<\kappa_{t}<1$ by Lemma 1.

\section{References}

Ahnert, H., Kenny, G., 2004. Quality Adjustment of European Price Statistics and the Role for Hedonics. ECB Occasional Paper Series No. 15.

Bernard, A., Eaton, J., Jensen, B., Kortum, S., 2003. Plants and Productivity in International Trade. The American Economic Review XCIII, 1268-1290.

Brůha, J., Podpiera, J., 2010. Real Exchange Rate in Transition Economies: The Role of Different Investment Margins. The Economics of Transition 18(3), pp. 599-628.

Cincibuch, M., Podpiera, J., 2006. Beyond Balassa-Samuelson: Real Appreciation in Tradables in Transition Countries. Economics of Transition, vol. 14(3) 2006, pp. 547-573.

Dury, K., Oomen, Ö., 2007. The real exchange rate and quality improvements. Bank of England Working Paper 320. 
Égert, B., Halpern L., MacDonald, R., 2006. Equilibrium Exchange Rates in Transition Economies: Taking Stock of the Issues. Journal of Economic Surveys. 20(2). 257-324.

Fabrizio, S., Igan, D., Mody, A., 2007. The Dynamics of Product Quality and International Competitiveness. IMF Working Paper WP/07/97.

Ghironi, F., Melitz, M., 2005. International Trade and Macroeconomic Dynamics with Heterogeneous Firms. Quarterly Journal of Economics CXX, 865-915.

Hallak, J.C., Schott, P.K., 2008. Estimating Cross-Country Differences in Product Quality. NBER Working paper 13807, February 2008.

Melitz, M., 2003. The Impact of Trade on Intra-Industry Reallocation and Aggregate Industry Productivity. Econometrica 71, 1695-1725.

Podpiera, J., Raková, M., 2008. Degree of Competition and Exchange Rate Changes: Evidence from a Panel of Exporting Firms. Czech Journal of Economics and Finance 58 (1-2), 38-56.

Roland, G. 2004. After Enlargement: Institutional Achievements and Prospects in the New Member States. Chapter 3 in C. Detken, V. Gaspar, G. Noblet (Eds.) 'The New EU Member States Convergence and Stability', Proceedings of The Third ECB Central Banking Conference, 2004, pp. 35-58.

Rotemberg, J., Woodford, M., 1992. Oligopolistic Pricng and the Effects of Aggregate Demand on Economic Activity. Journal of Political Economy 100, 1153-1207.

Schmitt-Grohe, S., Uribe, M., 2003. Closing Small Open Economy Models. Journal of International Economics 61, 163-185.

Young, A., 1998. Growth without Scale Effects. Journal of Political Economy 106, 41-63. 